\title{
Over the Counter Oral Appliances: Cause for Concern?
}

\author{
Jean-François Masse, DMD, MSc, Diplomate, ABDSM
}

Editor-in-Chief Journal of Dental Sleep Medicine Universite Laval, Quebec City, Quebec, Canada

The field of Dental Sleep Medicine is evolving rapidly. Because patients are becoming increasingly aware of the treatment of OSA with oral appliances, it is estimated that the number of dental devices delivered in the next 5 years will increase by $15.7 \%$ yearly. ${ }^{1}$ This level of growth regularly brings new players to the field with new ideas, which is a good thing. The downside of this situation is that not all these newcomers are created equal and we see that for some, the benefit to the patient is not always apparent. Among these we find an increasing number of direct-to-consumer marketing: over-the-counter dental appliances sold directly to consumers through the internet and in drugstores. With a median household income of $\$ 59000$ in the US, ${ }^{2}$ one certainly cannot blame consumers (note consumers, not patients in this case) from wanting to identify a less expensive alternative than what the dental community is offering. If I were a snorer with little knowledge on the subject, I would be the first to buy this type of device. To be fair, some people may very well be served with overthe-counter (OTC) sleep appliances. We also see that some OTC companies appear more earnest than others about their efforts to seriously make a business out of selling budget-priced appliances to consumers. The problem is not the device; the problem lies elsewhere.

What should we do about this trend? The answer to that question is more complicated than it seems at first glance.

We must first make a distinction between boil and bite appliances recommended or delivered by dentists (which are considered temporary or trial appliances in some instances) and those appliances bought directly by consumers at drugstores and on the internet. Even if on occasion the two types of appliances are very similar in design, there is a major distinction: service provided by a dentist qualified in dental sleep medicine.

Every one of us who has had the opportunity to deliver a boil and bite appliance to one of our patients knows how challenging this can be: even in ideal cases, we may encounter retention problems, tooth discomfort, jaw pain... In fact, even with a custom-made appliance and careful follow-up by a qualified dentist, things do not always go as planned, hence the publication of a thorough review of the literature on side effects and its management in last year's JDSM. ${ }^{3}$ One can only imagine what can happen when consumers are left to themselves to choose and adjust a device with no dental sleep knowledge. We are indeed left to our imagination as there no in-depth studies could be identified that discuss outcomes of direct-to-consumer OA.

A few research papers ${ }^{4-8}$ do however address the topic of boil and bite appliances. It must be recognized that the patients involved in these studies had all been medically evaluated by sleep physicians and qualified dentists had examined them to make sure they would be good candidates for oral appliance therapy. The boil and bite appliances were also selected by the investigators with some knowledge in appliance design. One has to keep in mind that the patients' circumstances in these cases are potentially very different from an unevaluated consumer shopping on the internet for a snoring device.

Even though there is heterogeneity in these studies' designs, we can draw the following conclusions:

- Boil and bite appliances may help in reducing snoring and possibly the sleep apnea hypopnea index.

- When compared, custom-made appliances approved for the treatment of OSA are more effective in reduction of the AHI than boil and bite devices.

- Comfort, and thus compliance, is a major hindrance in boil and bite appliances compared to custom made appliances. Even though some patients were evaluated for only a very short period of time, comfort nevertheless appeared to be an issue.

It is important to remember that these results came from supervised studies. Thus, at their best, OTC appliances are not likely to offer superior results than the boil and bite devices used in these studies.

We also know from other studies that tooth movement is very common even with custom made oral appliances and proper follow-up by the sleep dentist. ${ }^{3}$ We can thus assume that there is a great risk that unsupervised use of over the counter dental device can 
result in occlusal discrepancies that will cost a lot more to resolve than the cost of an oral appliance made by a qualified dentist. ${ }^{9}$

Despite all the evidence available to us and to the public, inexpensive, one-size-fits-all oral appliances are not going to disappear. In fact, it seems that we are hearing more and more about these products. I now have patients who have used the OTC appliance before their appointment to see if it made sense to buy the custommade. I tell them that the custom-made will be even better, and am dismayed to think about the others who unsuccessfully tried over-the-counter devices and decided not to proceed with the real thing because they could not tolerate the one-size-fits-all appliance.

So, what can be done? I do not see how the AADSM alone can do more than it does right now by constantly promoting the highest standards in the treatment of OSA and snoring by dentists. The AASM should also be concerned as it is not in the public interest to opt for treatment without proper evaluation. Both associations should find a way to educate the public about this situation. And since we cannot keep every internet enthusiast from purchasing OTC devices, it is our duty to inform the patients, the sleep physicians, pharmacists and our dental colleagues about the risks of using one-sizefits-all appliances. We must emphasize to the patient that the real value of the treatment we offer is the quality of the service we provide and not simply the appliance that is delivered. The problem is not the cost of the device; it is about the value of the device offered by a qualified dentist. We must communicate better why we do what we are doing but recognize that whatever we do, some patients will always opt for the cheapest solution, whether or not it is in their best interest.

\section{CITATION}

Masse, JF. Over the Counter Oral Appliances: Cause for Concern?. J Dent Sleep Med. 2019;6(1)

\section{REFERENCES}

1. Sleep Apnea Oral Appliances Market by Product (Mandibular Advancement Devices (Mad) \& Tongue-Retaining Devices (TRD)), Type (Physician Prescribed/Customized Oral Appliances \& Online OTC Oral Appliances) - Global Forecasts to 2023. Markets and Markets. https://www.marketsandmarkets.com/Market-Reports/sleepapnea-oral-appliances-market-105423877.html. May, 2018. Accessed December 21, 2018.
2. Guzman GG. Household income: 2017. The United States Census Bureau. https://www.census.gov/content/dam/Census/library/publications/ 2018/acs/acsbr17-01.pdf. September, 2018. Accessed December 21, 2018.

3. Sheats RD, Schell TG, Blanton AO, et al. Management of side effects of oral appliance therapy for sleep-disordered breathing. J Dent Sleep Med. 2017;4(4):111-125.

4.Banhiran W, Assanasen P, Nopmaneejumrudlers C, et al. Adjustable thermoplastic oral appliance versus positive airway pressure for obstructive sleep apnea. Laryngoscope. 2018 Feb;128(2):516-522.

5. Makihara E, Kawano T, Miyajima R, Masumi SI, Enciso R, Clark GT. Assessment of oral appliance for obstructive sleep apnea patients. Clin Exp Dent Res. 2016 Jul 29:2(2):155-161.

6. Tsuda H, Almeida FR, Masumi S, Lowe AA. Side effects of boil and bite type oral appliance therapy in sleep apnea patients. Sleep Breath. 2010 Sept;14(3):227-232.

7. Vanderveken OM, Devolder A, Marklund M, et al. Comparison of a custommade and a thermoplastic oral appliance for the treatment of mild sleep apnea. Am J Respir Crit Care Med. 2008 Jul 15;178(2):197202.

8. Quinnell TG, Bennett M, Jordan J, et al. A crossover randomised controlled trial of oral mandibular advancement devices for obstructive sleep apnoea-hypopnoea (TOMADO). Thorax. 2014 Oct;69(10):938-45.

9. LA FRAC+TURE. ICI Radio-Canada Télé. https://ici.tou.tv/lafacture/s19e03. September 24, 2013. Accessed December 21, 2018 .

\section{SUBMISSION AND CORRESPONDENCE INFORMATION}

\section{Submitted in final revised form December 21, 2018}

Address correspondence to: Jean-François Masse, Professor, Universite Laval, 2780 Masson \#200, Quebec City, QC, G1P 1J6, Canada; Tel: 418871-1447; Fax: 418-871-4983; Email: jeanfrancois.masse@fmd.ulaval.ca 